*Pós- Doutorado em Ciências Sociais Aplicadas em 2016 pela Universitá Degli di Messina (UNIME)

Doutor em Direito em 2009 pela Pontifícia Universidade Católica de Minas Gerais (PUC-MG)

Mestre em Direito em 2003 pela Pontifícia Universidade Católica de Minas Gerais (PUC-MG)

Especialsit em Direito em 1999 pela Universidade Gama Filho (UGF)

Graduado em Direito em 1994 pela Pontifícia Universidade Católica de Minas Gerais (PUC-MG)

E-mail: elcionacurrezende@ yahoo.com.br

\footnotetext{
**Mestrado em andamento em Direito pela Faculdades Milton Campos (FMC)

Especialista em Direito em 2018 pela Faculdade Arnaldo Janssen Graduada em Direito em 2015 pela Pontifícia Universidade Católica de Minas Gerais (PUC-MG)

E-mail: marcellemaria.adv@ gmail.com
}

\section{A FRAUDE COMO ELEMENTO \\ SUBJETIVO ESSENCIAL À APLICAÇÃO \\ DA DESCONSIDERAÇÃO INVERSA DA \\ PERSONALIDADE JURÍDICA NAS "HOLDINGS" \\ FAMILIARES}

\author{
FRAUD AS A SUBJECTIVE ELEMENTARY \\ ESSENTIAL TO THE APPLICATION OF THE \\ INVERSE DISREGARD OF LEGAL PERSONALITY IN \\ FAMILY HOLDINGS
}

\section{Elcio Nacur Rezende* Marcelle Mariá Silva de Oliveira**}

Como citar: REZENDE, Elcio Nakur; OLIVEIRA, Marcelle Mariá Silva de. A fraude como elemento subjetivo essencial à aplicação da desconsideração inversa da personalidade jurídica das "holdings" familares. Scientia Iuris, Londrina, v. 23, n. 2, p. 110-126, jul. 2019. DOI: 10.5433/2178-8189.2019v23n2p110. ISSN: $2178-8189$

Resumo - Apresenta-se, sob o prisma do direito brasileiro, um estudo sobre a Teoria da Desconsideração Inversa da Personalidade Jurídica e a possibilidade de sua aplicação à chamada "holding" familiar, bem como uma análise quanto à imprescindibilidade da existência do intuito fraudulento. $\mathrm{O}$ trabalho é expositivo e analítico, porquanto é feito um exame em relação aos institutos abordados, bem como uma busca por decisões judiciais acerca da temática. A justificativa, assentada na análise de fontes primárias e secundárias de pesquisa e exposta pelo método lógico-indutivo é a busca por respostas acerca do entendimento doutrinário e do comportamento do poder judiciário em situações análogas à ora descrita, para se chegar à conclusão de que é indispensável a constatação de existência do intuito fraudulento para aplicação da Desconsideração Inversa da Personalidade jurídica às "holdings" familiares, sob pena de banalização do instituto.

Palavras-chave: Holding, holding familiar, intuito fraudulento, desconsideração inversa da personalidade jurídica, entendimento dos tribunais.

Abstract - It is presented, under the prism of Brazilian law, a study about the theory of inverse disregard of legal personality and the possibility of its application to the so-called family holding company, as well as an analysis about the indispensability of the 
existence of the fraudulent intention. The work is expositive and analytical, since an examination is made in relation to the institutes covered, as well as a search for judicial decisions on the subject. The justification, based on the analysis of primary and secondary sources of research and exposed by the logic-inductive method, is the search for answers about the doctrinal understanding and behavior of the judiciary in situations, in order to arrive at the conclusion that it is indispensable to verify the existence of the fraudulent intention to apply the inverse disregard of legal personality to the family holdings, under penalty of banalization of the institute.

Keywords: Holding, family Holding, fraudulent intention, disregard of legal personality, understanding of the courts. 


\section{INTRODUÇÃO}

O presente estudo objetivará uma análise das "holdings" familiares, que vêm sendo muito utilizadas no Brasil com o objetivo de gerir o patrimônio de determinado núcleo familiar e promover o planejamento sucessório e tributário do acervo, podendo, se utilizada da forma correta e imbuída de boas intenções, ser extremamente vantajosa para os fins a que se presta.

O texto será elaborado por meio da análise bibliográfica e jurisprudencial acerca do assunto, sendo desenvolvido em três capítulos, sendo que o primeiro apresentará o instituto geral da "holding", agregando aspectos acerca de sua criação, conceito e utilização, até adentrar, especificamente, na modalidade familiar, que, nada mais é que a sociedade "holding" constituída no seio de determinada família visando a gestão eficiente do patrimônio e da sucessão daquele acervo.

O segundo capítulo trará o conceito de desconsideração da personalidade jurídica, a qual, em sua modalidade habitual, compreende a possibilidade de afetação do patrimônio dos sócios por dívidas da sociedade, desprezando, portanto, o princípio da autonomia patrimonial. Serão destacadas, ainda, as recentes alterações legislativas que normatizaram a sua modalidade inversa, que, ao contrário, implica na desconsideração da personalidade do sócio, a fim de atingir o patrimônio da sociedade empresária por dívidas contraídas pessoalmente.

Nesse sentido, observa-se que, não raro, as possibilidades legais postas à disposição são utilizadas de forma distorcida, com a finalidade única de se obter proveito em detrimento de outros ou do Estado. Assim, torna-se evidente que a constituição da "holding" familiar, quando malintencionada, pode abrir margem para a prática de abusos e fraudes diversas, tanto em prejuízo ao fisco quanto a credores particulares.

Portanto, tendo como marco teórico as lições de Márcio Tadeu Guimarães Nunes e Regis Velasco Fichtner Pereira, será promovida uma análise crítica acerca dos institutos abordados, verificando a possibilidade de se aplicar, em uma situação concreta, a desconsideração inversa da personalidade jurídica, quando da constatação de abusos, fraudes ou inadimplência dos membros da família que constituíram a "holding" familiar,

Buscará, ainda, compreender se o elemento subjetivo compreendido pela intenção de fraudar, isto é, o dolo de causar prejuízo a outrem, é imprescindível à aplicação da desconsideração da personalidade jurídica, neste caso, especialmente da sua modalidade inversa, em sede de "holdings" familiares. Assim sendo, o problema ora apresentado se traduz no seguinte questionamento: o elemento "intenção de fraudar" é imprescindível na aplicação da desconsideração inversa da personalidade jurídica, especialmente nas "holdings" familiares?

\section{2 "HOLDINGS", CONCEITO E ESPÉCIES}

As sociedades empresárias "holdings" são pessoas jurídicas que "atuam como titulares de bens e direitos, o que pode incluir bens imóveis, bens móveis, participações societárias, propriedade 
industrial (patente, marca etc.), investimentos financeiros etc.” (MAMEDE; MAMEDE, 2017, p. 13/14).

Tratam-se, portanto, das sociedades que têm como objetivo deter certo patrimônio material ou imaterial; sendo certo que, caso seu único propósito seja o de deter a participação societária em outras sociedades, ela será uma "holding” pura. De outro modo, a "holding” será mista se possuir em seu objeto social não somente a participação em outras empresas, mas, também, a "exploração de alguma atividade empresarial diversa" (DA SILVA; ROSSI, 2017, p. 22).

Destaca-se que "holding" não é um tipo societário, mas uma definição que leva em conta a finalidade a que a sociedade empresária, que poderá se constituir sob as várias formas autorizadas em lei, se destina. Para exemplificar, faz-se necessária a leitura do parágrafo $3^{\circ}$ do art. $2^{\circ}$ da Lei de Sociedades Anônimas (Lei $n^{\circ}$ 6.404/76), o qual foi o primeiro texto normativo a admitir expressamente a sociedade empresária que tem como objeto a participação em outras sociedades, senão vejamos:

Art. $2^{\circ}$ Pode ser objeto da companhia qualquer empresa de fim lucrativo, não contrário à lei, à ordem pública e aos bons costumes.

$\S 1^{\circ}$ Qualquer que seja o objeto, a companhia é mercantil e se rege pelas leis e usos do comércio.

$\S 2^{\circ} \mathrm{O}$ estatuto social definirá o objeto de modo preciso e completo.

$\S 3^{\circ} \mathrm{A}$ companhia pode ter por objeto participar de outras sociedades; ainda que não prevista no estatuto, a participação é facultada como meio de realizar o objeto social, ou para beneficiar-se de incentivos fiscais.

Observa-se, pois, que uma sociedade empresarial constituída sob a forma de sociedade anônima poderá ter por objeto a participação em outras sociedades, caracterizando-se, assim, a "holding". Do mesmo modo, ela poderá ser uma sociedade limitada, com todas as suas características decorrentes da lei, de modo que, o que a caracterizará como "holding" é o seu objeto social, a atividade a que se presta a exercer.

O uso das "holdings" surgiu no Brasil após a resolução no 469 do Banco Central, de 07/04/1978, e, segundo Gladston Mamede e Eduarda Cotta Mamede (2017), tem se tornado comum a sua constituição com o objetivo de deter e administrar determinado patrimônio familiar e, por conseguinte, realizar um planejamento sucessório e tributário desse acervo, são as denominadas "holdings" familiares.

Ultrapassando a divisão básica de "holdings" (pura e mista), Gladston Mamede e Eduarda Cotta Mamede (2017, p. 16) afirmam que as referidas empresas poderão, ainda, ser nominadas como "holding de controle, de participação, de administração, patrimonial ou imobiliária" de acordo com o objeto social que possuírem. Nesse sentido, as "holdings" patrimoniais são as constituídas com a finalidade de ser proprietária de determinado patrimônio; por sua vez, as imobiliárias terão objetivo de deter patrimônio imobiliário (MAMEDE; MAMEDE, 2017, p. 16).

Assim, a "holding" familiar, que não é assim conceituada considerando o seu objeto 
social, poderá se revestir de qualquer uma das formas acima, já que, na verdade, a sua denominação considera o fato de ela estar enquadrada no âmbito familiar, contribuindo para o planejamento patrimonial, fiscal e sucessório daquela família, conforme ensinam Gladston Mamede e Eduarda Cotta Mamede (2017, p. 16):

Sua marca característica é o fato de se enquadrar no âmbito de determinada família, e, assim, servir ao planejamento desenvolvido por seus membros, considerando desafios como organização do patrimônio, administração de bens, organização fiscal, sucessão hereditária etc.

Ou seja, do mesmo modo, a "holding" familiar será imobiliária se se prestar à gestão do patrimônio imobiliário de terminado núcleo familiar; será patrimonial se seu objetivo for o de deter e administrar o patrimônio familiar como um todo, compreendendo bens móveis ou imóveis; será de participação, se tiver como objeto a participação em outras sociedades empresárias da mesma família e assim por diante.

Evidente, então, que a existência de uma "holding" familiar demanda adequação específica ao contexto da família que a constituí, considerando o tipo de patrimônio, de atividade exercida, os membros da família, a saber:

A gestão adequada do patrimônio por intermédio de uma Holding familiar pressupõe, como medida preliminar, a constituição adequada da pessoa jurídica, a qual pode ser gestada de inúmeras formas societárias, a depender do caso concreto e do futuro direcionamento das quotas sociais entre herdeiros necessários e os eventuais beneficiários ou legatários. (OLIVEIRA, 2013. p. 7).

Portanto, é de suma importância lembrar que a atividade empresária pode ser exercida por todos aqueles que estiverem em pleno gozo da capacidade civil e não estejam submetidas a qualquer impedimento legal, ou seja, os incapazes não poderão constituir sociedade empresária, mas somente continuar a que já exercia enquanto capaz, conforme previsão do art. 974 do Código Civil: "poderá o incapaz, por meio de representante ou devidamente assistido, continuar a empresa antes exercida por ele enquanto capaz, por seus pais ou pelo autor de herança”.

Além do mais, extremamente pertinente ao assunto é saber que há proibição legal expressa da contratação de sociedade por parte de cônjuges casados em regime de comunhão total de bens, tal como determina o art. 977 do Código Civil: "faculta-se aos cônjuges contratar sociedade, entre si ou com terceiros, desde que não tenham casado no regime da comunhão universal de bens, ou no da separação obrigatória".

Existem, ainda, as proibições legais quanto ao exercício da administração das sociedades, situações em que as pessoas impedidas poderão apenas figurar como sócias, as quais estão contidas no $§ 1^{\circ}$ do art. 1.011 do Código Civil:

§1o Não podem ser administradores, além das pessoas impedidas por lei especial, 
os condenados a pena que vede, ainda que temporariamente, o acesso a cargos públicos; ou por crime falimentar, de prevaricação, peita ou suborno, concussão, peculato; ou contra a economia popular, contra o sistema financeiro nacional, contra as normas de defesa da concorrência, contra as relações de consumo, a fé pública ou a propriedade, enquanto perdurarem os efeitos da condenação.

Especificamente no que toca às "holdings" familiares, imperioso destacar que, uma vez constituídas sob qualquer uma das formas societárias admitidas, e, considerando o contexto familiar no qual se insere, a sociedade terá como sócios, inicialmente, os patriarcas da família, os quais, via de regra, integralizarão o capital social, mediante a transferência de seu patrimônio pessoal, sendo certo que não há impeditivo para a alteração da estrutura de uma sociedade empresarial já existente no seio da família (por exemplo, um restaurante), de modo a se tornar uma "holding", a fim de estruturar a sucessão empresarial e familiar.

Posteriormente, na forma mais usual, os patriarcas doarão as cotas sociais aos seus sucessores, constando as cláusulas de inalienabilidade, incomunicabilidade, impenhorabilidade, reversibilidade e com a reserva do usufruto, delimitando como se dará a administração da sociedade na sua ausência. No entanto, frise-se, esta não é a única forma de organização patrimonial sucessória, pois, a depender da estrutura familiar que permeia a constituição da "holding", será possível optar por outros mecanismos legais previstos, como por exemplo, o testamento, ou então, o patrimônio (cotas societárias) poderá ser partilhado através do inventário, dentre outros.

O que muitos autores já citados defendem é que esta estruturação acarretará não somente a organização adiantada da sucessão familiar, como também o melhor aproveitamento do patrimônio e o planejamento tributário/fiscal, inclusive com economias substanciais. Sabendo disso, observase que, de fato, a constituição de uma "holding" familiar pode ser muito benéfica para a organização do patrimônio (seja ele imóvel, constituído por outras sociedades, etc) de uma família.

No entanto, não se pode perder de vista que, criar uma pessoa jurídica para a qual se transfere todos os bens particulares da família, delegando a gestão desses bens, pode abrir margem para diversos tipos de fraudes e abusos, que poderiam ensejar a desconsideração da personalidade jurídica, conforme se verá.

\section{DESCONSIDERAÇÃO INVERSA DA PERSONALIDADE JURÍDICA}

O direito empresarial brasileiro tem como referência o princípio da autonomia patrimonial, pelo qual se reconhece a independência entre os patrimônios do(s) sócio(s) e da pessoa jurídica da qual ele(s) faz(em) parte. Em outras palavras, conceber a autonomia entre os patrimônios dos sócios e da sociedade implica em admitir que os referidos patrimônios são distintos e dissociados um do outro, o que, em última instância, viabiliza a limitação da responsabilidade dos sócios. Nesse sentido, como desdobramento do referido princípio, tem-se, ainda, que as dívidas contraídas pela sociedade não dizem respeito e (em regra) não afetam o patrimônio pessoal dos sócios, e viceversa. 
Tal como ensina Otávio Joaquim Rodrigues Filho (2016, p. 85), o referido princípio surgiu como uma resposta aos anseios sociais, no sentido de se atrair pessoas dispostas a exercer a atividade empresarial e, consequentemente, gerar empregos:

O reconhecimento gradativo da personalidade jurídica tal qual se dá na atualidade, inclusive com a nítida separação de patrimônios e responsabilidades, fora antes uma necessidade para atrair capitais, limitando os riscos inerentes à atividade comercial. A função econômica do instituto evidencia-se, assim, como mola propulsora para a produção de riquezas e geração de empregos.

Assim, nota-se o exercício da empresa deveria pautar-se, também, na sua função social, isto é, atendendo também aos interesses sociais (RODRIGUES FILHO, 2016), o que faz com que a referida autonomia patrimonial ora discutida não seja absoluta, já que, uma vez presente a situação de abuso da personalidade jurídica é possível a afetação do patrimônio do sócio em razão de dívidas contraídas pela pessoa jurídica, o que se denomina desconsideração da personalidade jurídica.

O professor Marcelo Moraes Tavares (2008) ensina que a teoria da desconsideração da personalidade jurídica passou a ser objeto de estudo dos aplicadores do direito a partir do século XIX, quando evidenciadas práticas abusivas cometidas por sócios de empresas, sob o manto da personalidade jurídica, sendo que, para ele, a decisão judicial pioneira sobre o assunto teve lugar nos Estados Unidos, no ano de 1809, no seio do caso que teve como partes litigantes o Banco dos Estados Unidos e a empresa Deveaux.

Nada obstante diversos autores entendam que a referida decisão judicial não tenha abordado diretamente a desconsideração da personalidade jurídica como conhecemos hoje, isto é, com efeitos de afetação do patrimônio dos sócios, fato é que foi de extrema importância para a construção da referida teoria. Por conseguinte, o marco que inaugurou o nascimento da teoria da desconsideração da personalidade jurídica de forma direta foi a decisão proferida no caso "Salomon vs Salomon \& CO”, do ano de 1897, na Inglaterra, que, embora desfavorável em segunda instância, suscitou a discussão e os fundamentos que, por fim, a originaram. Naquela ocasião, o magistrado inglês entendeu que Aaron Salomon, já empresário individual, ao constituir a sociedade, realizou operação fraudulenta, se aproveitando dela para se isentar da responsabilidade e dos riscos de provenientes da atividade econômica (PARENTONI, 2018).

Contudo, tal fenômeno somente chegou ao Brasil em 1969, por iniciativa de Rubens Requião, que suscitou a discussão sobre o assunto em conferência realizada na Universidade do Paraná (GUIMARÃES, 2004). A efetiva normatização, contudo, somente se deu no ano de 1990, com o Código de Defesa do Consumidor, especificamente em seu art. 28:

Art. 28. O juiz poderá desconsiderar a personalidade jurídica da sociedade quando, em detrimento do consumidor, houver abuso de direito, excesso de poder, infração da lei, fato ou ato ilícito ou violação dos estatutos ou contrato social. A desconsideração também será efetivada quando houver falência, estado de insolvência, encerramento ou inatividade da 
pessoa jurídica provocados por má administração.

(...)

$\S 5^{\circ}$ Também poderá ser desconsiderada a pessoa jurídica sempre que sua personalidade for, de alguma forma, obstáculo ao ressarcimento de prejuízos causados aos consumidores.

A partir de tal fato, a legislação brasileira passou a trazer novas disposições a respeito do assunto, até que o então novo Código Civil, que entrou em vigor no ano de 2003, previu, em seu art. 50, nova determinação direta e expressa sobre a aplicação da teoria da desconsideração da personalidade jurídica, conforme se vê:

Art. 50. Em caso de abuso da personalidade jurídica, caracterizado pelo desvio de finalidade, ou pela confusão patrimonial, pode o juiz decidir, a requerimento da parte, ou do Ministério Público quando lhe couber intervir no processo, que os efeitos de certas e determinadas relações de obrigações sejam estendidos aos bens particulares dos administradores ou sócios da pessoa jurídica.

Observa-se que a teoria da desconsideração da personalidade jurídica em sede de relações consumeristas é mais abrangente e menos rigorosa, como resultado do próprio cunho protetivo daquela codificação, o que torna imperioso fazer uma diferenciação entre ambas as espécies do instituto em comento. Nesse sentido, convém destacar que para a Teoria Maior da desconsideração da personalidade jurídica, aquela abraçada pelo Código Civil e defendida por Rubens Requião, para se ignorar a autonomia patrimonial das sociedades empresárias é necessário que se demonstre a fraude ou abuso do direito:

É de nítida concepção subjetivista a teoria esposada por Rubens Requião quando
se trata da verificação da fraude, que deve ser vista pelo seu aspecto anímico,
abrindo exceção apenas às hipóteses de abuso do direito, que se configuraria
independentemente do propósito de prejudicar outrem. Toma o doutrinador como
ponto de partida a ideia de que a pessoa jurídica é uma realidade que se passa
no mundo jurídico, e não na "vida sensível", que tem na sua concessão, como
uma das principais consequências, a autonomia patrimonial. Nesse contexto,
a desconsideração nega o absolutismo do direito de personalidade jurídica,
posto que a teoria é vista como declaração de sua ineficácia para certos efeitos,
permanecendo, contudo, "incólume para outros fins legítimos". (RODRIGUES
FILHO, 2016. p. 63).

Noutro passo, para Teoria Menor (Código de Defesa do Consumidor) basta a demonstração de insuficiência patrimonial da sociedade, quando, de alguma forma, a personalidade jurídica for obstáculo ao ressarcimento dos prejuízos causados aos consumidores.

Destaca-se, ainda, que, após consagrada a teoria da desconsideração da personalidade jurídica, diversos aplicadores do direito passaram a admitir a sua aplicação de modo contrário, isto é, quando os atos fraudulentos são praticados pela pessoa natural que já haveria desfeito de seu patrimônio pessoal em favor da sociedade. A partir daí os tribunais brasileiros começaram a 
aplicar a teoria de forma inversa em casos práticos. Para ilustrar, colaciona-se decisão emblemática proferida no STJ a respeito do assunto, em que, com base em uma interpretação teleológica do art. 50 do Código Civil, e, visando combater a utilização indevida do ente societário pelos sócios, afastou-se a autonomia patrimonial da sociedade para atingir seu patrimônio, como medida de responsabilização por obrigações contraídas pessoalmente pelo sócio controlador:

PROCESSUAL CIVIL E CIVIL. RECURSO ESPECIAL. EXECUÇÃO DE TÍTULO JUDICIAL. ART. 50 DO CC02. DESCONSIDERAÇÃO DA PERSONALIDADE JURÍDICA INVERSA. POSSIBILIDADE. I - A ausência de decisão acerca dos dispositivos legais indicados como violados impede o conhecimento do recurso especial. Súmula 211/STJ. II-Os embargos declaratórios têm como objetivo sanear eventual obscuridade, contradição ou omissão existentes na decisão recorrida. Inexiste ofensa ao art. 535 do CPC, quando o Tribunal a quo pronuncia-se de forma clara e precisa sobre a questão posta nos autos, assentando-se em fundamentos suficientes para embasar a decisão, como ocorrido na espécie. III - A desconsideração inversa da personalidade jurídica caracteriza-se pelo afastamento da autonomia patrimonial da sociedade, para, contrariamente do que ocorre na desconsideração da personalidade propriamente dita, atingir o ente coletivo e seu patrimônio social, de modo a responsabilizar a pessoa jurídica por obrigações do sócio controlador. IV - Considerando-se que a finalidade da disregard doctrine é combater a utilização indevida do ente societário por seus sócios, o que pode ocorrer também nos casos em que o sócio controlador esvazia o seu patrimônio pessoal e o integraliza na pessoa jurídica, conclui-se, de uma interpretação teleológica do art. 50 do CC02, ser possível a desconsideração inversa da personalidade jurídica, de modo a atingir bens da sociedade em razão de dívidas contraídas pelo sócio controlador, conquanto preenchidos os requisitos previstos na norma. $\mathrm{V}$ - A desconsideração da personalidade jurídica configurase como medida excepcional. Sua adoção somente é recomendada quando forem atendidos os pressupostos específicos relacionados com a fraude ou abuso de direito estabelecidos no art. 50 do CC02. Somente se forem verificados os requisitos de sua incidência, poderá o juiz, no próprio processo de execução, "levantar o véu" da personalidade jurídica para que o ato de expropriação atinja os bens da empresa. VI - À luz das provas produzidas, a decisão proferida no primeiro grau de jurisdição, entendeu, mediante minuciosa fundamentação, pela ocorrência de confusão patrimonial e abuso de direito por parte do recorrente, ao se utilizar indevidamente de sua empresa para adquirir bens de uso particular. VII - Em conclusão, a r. decisão atacada, ao manter a decisão proferida no primeiro grau de jurisdição, afigurou-se escorreita, merecendo assim ser mantida por seus próprios fundamentos. Recurso especial não provido. (STJ, REsp n. 948117 , Relatora MINISTRA NANCY ANDRIGHI, j. 22/06/2010).

Durante anos, a desconsideração da personalidade jurídica inversa continuou sendo aplicada pelos magistrados em situações concretas, com embasamento nas doutrinas existentes e interpretação teleológica do Código Civil, até que, com o advento no novo Código de Processo Civil, a referida teoria foi normatizada, conforme se lê em seu art. 133, parágrafo segundo: 
Art. 133. O incidente de desconsideração da personalidade jurídica será instaurado a pedido da parte ou do Ministério Público, quando lhe couber intervir no processo.

$\S 1$ o $\mathrm{O}$ pedido de desconsideração da personalidade jurídica observará os pressupostos previstos em lei.

$\S 20$ Aplica-se o disposto neste Capítulo à hipótese de desconsideração inversa da personalidade jurídica. BRASIL. Lei 13.105, de 16 de mar. de 2015.

A leitura do artigo acima colacionado demonstra, também, que a nova codificação processual passou a estabelecer a existência de um procedimento que deve preceder à aplicação da desconsideração da personalidade jurídica. Trata-se do incidente de desconsideração da personalidade jurídica, que determinou a implementação da ampla defesa e do contraditório nestas situações, de modo que, a efetiva desconsideração, inversa ou não, da personalidade jurídica, ocorrerá após dada a oportunidade aos envolvidos de se manifestarem e exercerem o contraditório.

Tais novidades legislativas representam avanço no sentido de o direito acompanhar as evoluções da sociedade, pois, não se pode olvidar que a movimentação que tem ocasionado o grande aumento no número de novas sociedades constituídas com o objetivo de deter e gerir o patrimônio de determinada família abre margem para inúmeras possíveis atividades fraudulentas, o que poderá ser combatido por meio da desconsideração inversa da personalidade jurídica

\subsection{Desconsideração Inversa da Personalidade Jurídica em "Holdings" Familiares}

Conforme visto, a constituição de "holdings" como alternativa para gestão de determinado patrimônio tem se tornado cada vez mais comum, existindo, inclusive, profissionais que defendem ser esta uma opção para garantir a "blindagem patrimonial” do acervo, além de, é claro, possibilitar o planejamento jurídico, tributário e sucessório. No entanto, além de falsa, a promessa de blindagem patrimonial pode se configurar em crime, tanto é assim que são conhecidos inúmeros casos de grandes operações policiais que investigaram empresas criadas com esse intuito.

Em sua obra "Blindagem Patrimonial e Planejamento Jurídico", Mamede e Mamede(2015) trazem à tona três dessas operações, dentre as quais, a denominada "Bicho Mineiro", realizada no estado de Minas Gerais, que se prestou a investigar a criação de sociedades empresárias e evasão do patrimônio com o fim de fraudar o fisco.

Assim, fica evidente a importância do assunto ora tratado, pois, diante de tudo que foi exposto até aqui, é possível, concluir pela existência de variadas possibilidades de utilização também das "holdings" familiares como meios de fraudar o fisco ou credores particulares. É que, nada obstante, em regra, o objetivo primordial dessa ferramenta seja o de facilitar a gestão do patrimônio, estruturar a empresa, planejar o aspecto tributário/fiscal que envolve a atividade e a transmissão do patrimônio e organizar a sucessão, não se pode perder de vista que a mente humana, muitas vezes, desvirtua-se a cria mecanismos para o mal, o ilegal, visando vantagens desmedidas e descabidas. Nesse contexto, torna-se extremamente relevante analisar a possibilidade de se 
garantir medidas efetivas contra tais práticas. Uma delas pode se configurar pela desconsideração da personalidade jurídica.

Nesse sentido, entendimento do Tribunal de Justiça do Estado de São Paulo, quando do julgamento do Agravo Interno de no 00786111620138260000 SP 0078611-16.2013.8.26.0000, reconhecendo a possibilidade de se desconsiderar o princípio da autonomia patrimonial para adentrar ao patrimônio da sociedade "holding" com o objetivo de solver dívidas contraídas pelo sócio, tendo em vista as evidências de que ele se utilizava da sociedade para ocultar seus bens e a existência de confusão patrimonial:

DESCONSIDERAÇÃO DA PERSONALIDADE JURÍDICA INVERSA Cumprimento de sentença - Executado é sócio de diversas empresas que atuam no ramo de venda/locação de automóveis, sendo que suas contas permanecem zeradas, Ainda, detém 99,99\% da empresa DTRÊS HOLDINGS LTDA cujo endereço, constante na Junta Comercial, não corresponde à real localização de seu estabelecimento. Fato que demonstra que o executado utiliza-se de referida sociedade unicamente para ocultar bens, pois, ao que tudo indica, referida empresa sequer está em atividade. Confusão patrimonial caracterizada - RECURSO PROVIDO. (TJ-SP - AI: 00786111620138260000 SP 007861116.2013.8.26.0000, Relator: Renato Rangel Desinano, Data de Julgamento: 15/08/2013, 36 Câmara de Direito Privado, Data de Publicação: 16/08/2013)

Portanto, fica claro que os tribunais brasileiros têm entendido que a aplicação da desconsideração da personalidade jurídica exige que os requisitos do art. 50 do Código Civil estejam satisfeitos, ou seja, deve haver o abuso da personalidade jurídica através da confusão patrimonial ou o desvio de finalidade, que culminem na insolvência do sócio.

No caso das "holdings" familiares quando se fala em confusão patrimonial, a grosso modo, pode-se dizer que a própria constituição de uma sociedade que tem como objetivo gerir o patrimônio pessoal/familiar ocasiona essa desordem, já que a subsistência da família permanece em torno daquele mesmo acervo. Por sua vez, o abuso da personalidade, configurado pelo desvio de finalidade, sob o enfoque ora defendido, é resultado da intenção fraudulenta das pessoas envolvidas, que constituem a pessoa jurídica visando se esquivar de obrigações pessoais, o que pode culminar em grave fraude, como inadimplência em relação a dívidas alimentares. É o caso observado no julgamento do Agravo de Instrumento no 817956/SC 2010.081795-6, no qual se constatou que o sócio se valia das sociedades empresariais para ocultar sua situação patrimonial, permanecendo sem bens em nome próprio, e, com isso se esquivando da prestação alimentar que lhe era imposta:

AGRAVO DE INSTRUMENTO. EXECUÇÃO DE ALIMENTOS. DECISÃO QUE DESCONSIDEROU INVERSAMENTE A PERSONALIDADE DA PESSOA JURÍDICA. ALEGAÇÃO DE QUE OS SÓCIOS NÃO AGIRAM DE FORMA ILEGAL. TODAS AS PROPRIEDADES MÓVEIS E IMÓVEIS UTILIZADAS PELO AGRAVANTE ESTÃO EM NOME DAS EMPRESAS. AUSÊNCIA DE BENS EM SEU NOME. Para a desconsideração inversa da 
personalidade jurídica de uma empresa é necessário que reste demonstrado nos autos o desvio de bens da pessoa física do sócio para a pessoa jurídica da qual possua controle absoluto, continuando ainda a usufruir de tais bens (AI n , Des. Saul Steil, fl. 72). In casu, verifica-se, claramente, nos autos, que o agravante utiliza-se de suas empresas para encobrir seus bens, não possuindo qualquer imóvel ou móvel em seu nome, colocando todos em propriedade da empresa Reis Engenharia de Obras Ltda. e da empresa Construtora Santa Catarina Ltda., conforme documentos anexados às fls. 171 a 176. Assim, há a possibilidade da desconsideração inversa da personalidade jurídica pois "o requerido se vale da empresa para mascarar a própria vida patrimonial, dado que, injustificadamente, não possui bens em seu nome, nem numerário o bastante ao pagamento do débito considerável. Impedir a desconsideração inversa da personalidade, neste caso particular, implica em prestigiar a fraude à lei, e ao descrédito à Justiça" (Juiz de Direito Flavio Andre Paz de Brum, na Ação Cautelar de Sequestro n. 023.10.049446-6, fl. 149). INTIMAÇÃO DA EMPRESA QUE TEVE SUA PERSONALIDADE DESCONSIDERADA. AUSÊNCIA DE NECESSIDADE. EXECUTADO SÓCIO MAJORITÁRIO E ADMINISTRADOR DA REFERIDA EMPRESA. PRINCÍPIO DA ECONOMIA E CELERIDADE PROCESSUAL. SUA INTIMAÇÃO PESSOAL PODE SER CONVALIDADA PARA A PESSOA JURÍDICA EM QUESTÃO. TEORIA DA APARÊNCIA. Com intuito de homenagear a celeridade e economia processual, tendo em vista que se trata de execução de alimentos, e a demora no julgamento castigará ainda mais a alimentante, a qual tem, atualmente, seu direito obstruído, a medida mais acertada é suprimir a intimação da empresa, uma vez que o agravante, já ciente de toda a situação jurídica instaurada, é seu sócio majoritário, além de ser o administrador isolado, podendo intervir caso entenda existir qualquer prejuízo à empresa. Aplica-se ainda, a Teoria da Aparência de Direito, a qual consiste em permitir que certas situações meramente aparentes e que não correspondem a realidade passem a ter validade jurídica como se fossem verdadeiras, objetivando a proteção do terceiro de boa-fé, no caso, a alimentante, na busca de um processo célere, justo e, por via indireta, preservando a credibilidade do ordenamento jurídico como um todo. NECESSIDADE DO CHAMAMENTO DA ESPOSA AOS AUTOS NÃO CONFIGURADA. QUANTIA REFERENTE AO QUINHÃO QUE A ESPOSA TEM POR DIREITO DECORRENTE DA COMUNHÃO UNIVERSAL DE BENS RESGUARDADA. AUSÊNCIA DE PREJUÍZO. RECURSO NÃO PROVIDO. Resguardada a parte da esposa como meeira do agravante, não há qualquer prejuízo do qual justifique a necessidade de sua presença no processo. Distintamente do que dispõe o art. 47 do Código de Processo Civil, in casu, a decisão proferida pode muito bem ser executada sem que haja qualquer necessidade de citação ou intimação de terceiros, uma vez que todos os direitos e garantias estão assegurados. (TJ-SC - AI: 817956 SC 2010.081795-6, Relator: Carlos Prudêncio, Data de Julgamento: 24/11/2011, Primeira Câmara de Direito Civil, Data de Publicação: Agravo de Instrumento n., da Capital)

Não é demais lembrar que, caso as dívidas dos sócios tenham sido contraídas antes da constituição da sociedade, e tenha esta sido criada com o intuito de se esquivar de tais dívidas, poderá estar presente o defeito do negócio jurídico denominado fraude contra credores, cujos requisitos estão delimitados no Código Civil: 
Art. 158. Os negócios de transmissão gratuita de bens ou remissão de dívida, se os praticar o devedor já insolvente, ou por eles reduzido à insolvência, ainda quando o ignore, poderão ser anulados pelos credores quirografários, como lesivos dos seus direitos.

Art. 159. Serão igualmente anuláveis os contratos onerosos do devedor insolvente, quando a insolvência for notória, ou houver motivo para ser conhecida do outro contratante.

E mais, conforme determina o próprio Código de Processo Civil, situações que ensejam a desconsideração, inversa ou não, da personalidade jurídica, podem configurar fraude à execução, o que garante aos credores medida para tentar coibir a prática fraudulenta em questão, a saber:

Art. 792. A alienação ou a oneração de bem é considerada fraude à execução:

I - quando sobre o bem pender ação fundada em direito real ou com pretensão reipersecutória, desde que a pendência do processo tenha sido averbada no respectivo registro público, se houver;

II - quando tiver sido averbada, no registro do bem, a pendência do processo de execução, na forma do art. 828;

III - quando tiver sido averbado, no registro do bem, hipoteca judiciária ou outro ato de constrição judicial originário do processo onde foi arguida a fraude;

IV - quando, ao tempo da alienação ou da oneração, tramitava contra o devedor ação capaz de reduzi-lo à insolvência;

$\mathrm{V}$ - nos demais casos expressos em lei.

Diante de tanto, observa-se que a existência de métodos que visam coibir práticas fraudulentas é imprescindível no ordenamento jurídico, e nesse sentido, o Código de Processo Civil trouxe importante inovação ao normatizar uma prática que já era há muito absorvida pelos nossos tribunais. Lado outro, a utilização consciente do mecanismo legal e eficiente para gestão e planejamento do patrimônio familiar pode e deve ser incentivada, na medida em que tem a capacidade de configurar grande evolução no sentido de continuidade da empresa.

\subsection{Elemento subjetivo essencial à aplicação da desconsideração da personalidade jurídica}

Conforme destacado, valer-se da constituição de uma sociedade empresária com o fim de organização patrimonial e sucessória, pode ser meio para obtenção de objetivos escusos. Nesse sentido, àqueles que possuírem intuito fraudulento, haverá medida sancionadora correspondente, fruto de criação doutrinária, jurisprudencial e legislativa, com o que concorda doutrina especializada:

A organização mercantil sob a forma de sociedade, para algumas mentes, acaba por incentivar a prática de atos escusos, se prestando a sociedade como ser imaterial servidor de abrigo ao fraudador. Nesse sentido, a doutrina e a jurisprudência desenvolveram mecanismos para descortinar a sociedade, retirando o véu protetor, viabilizando o alcance daqueles que se camuflam (GUIMARÃES, 2004, p. 230). 
A desconsideração da personalidade jurídica, especialmente para a Teoria Maior, adotada pelo Código Civil, exige a existência do elemento subjetivo traduzido na intenção de fraudar, no objetivo obscuro que rodeia a vida daquela sociedade empresária. Desse modo, tal como já dito alhures, a desconsideração da personalidade jurídica, prevista no art. 50 do Código Civil, terá lugar quando se constatar o abuso da personalidade jurídica, seja pelo desvio de finalidade ou pela confusão patrimonial.

Segundo Otávio Joaquim Rodrigues Filho (2016, p. 87), em obra específica sobre o tema, o instituto, nesses casos (diferentemente de como ocorre no direito consumerista), não objetiva combater o simples prejuízo material constatado, mas o abuso, a fraude à lei, o excesso, senão vejamos:

Não se trata de combater o simples prejuízo material, inerente ao risco da atividade comercial. É o abuso, o excesso, a fraude à lei ou ao contrato que desvinculam a atuação da pessoa jurídica de sua função social, produzindo a violação de direito que o ordenamento jurídico reputa mais valioso do que aquele relativo à personificação, sendo ele indisponível ou até mesmo disponível.

Nesse sentido, ainda segundo o referido jurista, "de maneira geral, toda fraude 'abre espaço à fraude à lei'; qualquer artifício que gera proveito indevido burla a proibição legal. O comando da norma, debaixo da aparência da legalidade" (RODRIGUES FILHO, 2016, p. 91). Assim, tendo como base a doutrina de Regis Fichtner Pereira (1994), segundo o qual, a fraude à lei demanda a existência da intenção de fraudar, o mesmo ocorrerá na desconsideração da personalidade jurídica.

Agrega-se, ainda, o argumento posto pelo jurista Márcio Tadeu Guimarães Nunes (2007), que já em 2007 constatou o uso indiscriminado dessa ferramenta, sem preocupação quanto à sua efetiva aplicabilidade, em detrimento de outras ferramentas oferecidas pelo direito, tais como a fraude contra credores ou a fraude à execução, mencionadas anteriormente, ou até mesmo a responsabilidade civil (quando se fala em desconsideração da personalidade jurídica em sua forma normal) (MACHADO, 2016).

\section{CONSIDERAÇÕES FINAIS}

As "holdings" são definidas como as sociedades que tem como escopo controlar outras sociedades empresárias, o chamado grupo empresarial, centralizando a tomada de decisões e a administração dessas empresas. Frise-se, nesse diapasão, que o grupo empresarial não possui personalidade jurídica, o que se tem é a existência de uma sociedade empresária tida como controladora, a "holding".

No entanto, a "holdings" podem assumir quaisquer modelos empresariais admitidos pelo Direito, que levam em consideração seu objeto social, podendo, portanto, ser classificadas como imobiliárias, de participação, patrimoniais, dentre outros.

No Brasil, tem se tornado comum a constituição de "holdings" com o objetivo de 
administrar o patrimônio familiar e, por conseguinte, realizar um planejamento sucessório e tributário desse patrimônio. São as denominadas "holdings" familiares. Diversos doutrinadores, a exemplo de Gladston Mamede e Eduarda Cotta Mamede (2017), entendem que a constituição de uma "holding" nesses moldes pode ser excelente alternativa para gestão do patrimônio familiar, pois possibilita um planejamento sucessório e tributário do acervo, além de ser excelente alternativa para organização e administração da empresa.

No entanto, não se pode perder de vista que, criar uma pessoa jurídica para a qual se transfere todos os bens particulares da família, delegando a gestão desses bens, pode abrir margem para diversos tipos de fraudes e abusos, tais como o esvaziamento do patrimônio pessoal a fim de se esquivar de dívidas contraídas. Diante de tanto, defende-se a possibilidade de aplicação, em situações concretas, da desconsideração inversa da personalidade jurídica, como forma de coibir abusos, fraudes ou inadimplência dos membros da família que figuram como sócios e/ou administradores dessa sociedade empresária ("holding" familiar), situação em que a autonomia patrimonial da empresa será ignorada, a fim de que seu patrimônio seja afetado para solver dívidas assumidas em nome dos sócios/administradores.

Nesses casos, imprescindível a constatação de que houve a intenção de fraudar na constituição daquela sociedade empresária, vez que, o Código Civil abarcou a Teoria Maior da desconsideração inversa da personalidade jurídica, a qual exige o abuso da pessoa jurídica como elemento essencial para sua caracterização. Não se ignora a dificuldade prática de provar a existência do elemento subjetivo traduzido no dolo de fraudar, no entanto, não se permite a banalização da desconsideração da personalidade jurídica sempre que se constatar fracasso ou prejuízo material.

\section{REFERÊNCIAS BIBLIOGRÁFICAS}

BAGNOLI, Martha Gallardo Sala. Holding imobiliária como Planejamento Sucessório. Coleção Academia-Empresa 17. São Paulo: Quartier Latin, 2016.

BRASIL. Lei 10.406, de 10 de jan. de 2002. Código Civil, Brasília, DF, jan. 2002.

BRASIL. Lei 6.404, de 15 de dez. de 1976. Lei de Sociedade por Ações, Brasília, DF, dez. 1976.

BRASIL. Lei 8.078, de 11 de set. de 1990. Código de Defesa do Consumidor, Brasília, DF, set. 1990.

BRASIL. Lei 13.105, de 16 de mar. De 2015. Código de Processo Civil, Brasília, DF, mar, 2015.

COELHO, Fábio Ulhoa. Manual de Direito Comercial. São Paulo: Saraiva, 2016. DA SILVA, Fábio Pereira; ROSSI, Alexandre Alves. Holding Familiar. Visão jurídica do planejamento societário, sucessório e tributário. São Paulo: Trevisan Editora, 2017. 
DUTRA, Joel Souza; DUTRA, Tatiana Almendra. Gestão do Processo Sucessório -

Preservando o negócio e a estratégia. São Paulo: Atlas, 2016.

FRANCO, Kleiton Serrão. Desconsideração da Personalidade Jurídica no Novo CPC: interpretação à luz do poder econômico. Dissertação de Mestrado. Universidade Presbiteriana Mackenzie. São Paulo, 2017.

GUIMARÃES, Márcio Souza. Aspectos Modernos da Teoria da Desconsideração da Personalidade Jurídica. Revista da EMERJ, v.7, n. 25, 2004. p. 229-243.

MACHADO, Hendel Sobrosa. Responsabilidade dos administradores e sócios além da desconsideração da personalidade jurídica. Rio de Janeiro: Lumen Iuris, 2016.

MAMEDE, Gladston Mamede; MAMEDE, Eduarda Cotta. Holding Familiar e suas vantagens. São Paulo: Atlas, 2017.

MAMEDE, Gladston Mamede; MAMEDE, Eduarta Cotta. Blindagem Patrimonial e Planejamento Jurídico. São Paulo: Atlas, 2015.

NUNES, Márcio Tadeu Guimarães Nunes. Desconstruindo a desconsideração da personalidade jurídica. São Paulo: Quartier Latin, 2007.

OLIVEIRA, Michele Cristina Souza Colla De. As Holdins Familiares e o planejamento sucessório no Direito Brasileiro. Trabalho de Conclusão de Curso de Especialização em Direito Empresarial, Centro Universitário Salesiano São Paulo. São Paulo, 2013.

PARENTONI, Leonardo. O incidente de desconsideração da personalidade jurídica no CPC/2015 [recurso eletrônico]. Porto Alegre, RS: Editora Fi, 2018.

PASQUALINI, Alexandre. A família no mundo contemporâneo e a transferência de riqueza. Belo Horizonte: Fórum, 2011.

PEREIRA, Regis Velasco Fichtner. A fraude à lei. Rio de Janeiro: Renovar, 1994.

PRADO, Roberta Nioac; COSTALUNGA, Karime; KIRSCHBAUM, Deborah. Sucessão Familiar e Planejamento Societário II. In: Estratégias Societárias, Planejamento Tributário e Sucessório. Coordenadores: Roberta Nioac Prado, Daniel Monteiro Peixoto e Eurico Marcos Diniz de Santi. São Paulo: Editora Saraiva, 2009.

RODRIGUES FILHO, Otávio Joaquim. DESCONSIDERAÇÃO DA PERSONALIDADE JURÍDICA E PROCESSO de acordo com o Código de Processo Civil de 2015. São Paulo: Malheiros, 2016.

SOUSA, Mara de Oliveira e. DESCARACTERIZAÇÃO DA AUTONOMIA PATRIMONIAL DA PESSOA JURÍDICA: desconsideração da personalidade societária inversa. Dissertação de Mestrado. Faculdade Milton Campos. Nova Lima, 2011.

TAVARES, Marcelo Moraes. A desconsideração da personalidade jurídica no processo de execução e no cumprimento de sentença. Dissertação de Mestrado. Faculdade Milton Campos. 
Nova Lima/MG, 2008.

TEIXEIRA, Daniele Chaves. Planejamento Sucessório: Pressupostos e Limites. $2^{\mathrm{a}}$ reimp. Belo Horizonte: Fórum, 2018.

Como citar: REZENDE, Elcio Nakur; OLIVEIRA, Marcelle Mariá Silva de. A fraude como elemento subjetivo essencial à aplicação da desconsideração inversa da personalidade jurídica das "holdings" familares. Scientia Iuris, Londrina, v. 23, n. 2, p. 110-126, jul. 2019. DOI: 10.5433/2178-8189.2019v23n2p110. ISSN: 2178-8189

Recebido em: 05/11/2018.

Aprovado em: 22/04/2019. 